\title{
Lophomonas blattarum parásito de cucarachas que causa neumonías infrecuentes en humanos
}

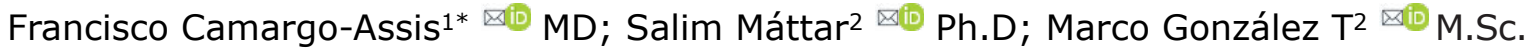

\begin{abstract}
${ }^{1}$ Clínicas Zayma y Universitaria, Medicina Integral CUMI. Universidad del Sinú. Montería. Colombia.
¿Universidad de Córdoba, Facultad de Medicina Veterinaria y Zootecnia, Instituto de Investigaciones Biológicas del Trópico, Montería. Colombia.

*Correspondencia: pcamassis@gmail.com
\end{abstract}

Lophomonas blattarum es un protozoo que parasita el tracto intestinal de termitas y cucarachas; pertenece al supergrupo Excavata, Parabasalia de primer rango y Cristamonadida de segundo rango (1). Son protistas unicelulares, flagelados, de vida libre, simbiontes y comensales endosimbiontes (2).

L. blattarum es eliminado en las heces de las cucarachas y como se ha demostrado para otros protozoos flagelados $(3,4)$, y de acuerdo con Martínez-Girón y Ribas (5) el organismo desarrolla quistes que pueden sobrevivir en el medio ambiente si las condiciones externas son adversas. Por tanto, los quistes de $L$. blattarum podrían ser inhalados hasta las vías respiratorias y con las condiciones adecuadas de humedad, temperatura y oxígeno, podrían sufrir exquistación. Este último proceso, se produce por contacto con agentes reductores, generalmente sales biliares o enzimas digestivas, aunque también puede producirse de forma espontánea. Así se producirían trofozoítos libres y por tanto móviles en el epitelio de las vías respiratorias, lo que probablemente afectaría a los humanos a través de receptores activados por proteasas (5), o por interacción con receptores específicos en el tracto respiratorio. Se plantea que los antígenos penetran a la mucosa del tracto gastrointestinal por disrupción y esto a su vez se correlaciona con un proceso alérgico, el cual es mediado por receptores de proteasas activados (6).

Chen y Meng (7) informaron el primer caso de infección pulmonar en humanos por L. blattarum en China en 1993. Sin embargo, en la literatura sólo se han reportado 140 casos entre 1993 y 2016 y la mayoría de ellos fueron en China, unos pocos en España y otros en Perú (8). En la India se reportó recientemente un caso de un paciente coinfectado con tuberculosis (2).

L. blattarum puede causar infecciones en una variedad de tejidos y órganos, incluyendo seno maxilar, aparato respiratorio y sistema reproductivo. Las infecciones son difíciles de diferenciar de otras con síntomas clínicos similares como neumonía y bronquitis. Alrededor del $96 \%$ de los casos están asociados a la infección del tracto respiratorio, aunque existen reportes de sinusitis e infecciones urinarias. El síntoma más frecuente es la tos sin expectoración y más del $50 \%$ de los pacientes presentan fiebre. Los hallazgos de laboratorio han mostrado algunos casos eosinofilia con opacidad y condensación de las imágenes al examen radiológico $(9,10)$.

Los síntomas de esta infección pulmonar parasitaria son similares a los de otras etiologías infecciosas respiratorias, como el asma bronquial, bronquiectasias, neumonía, abscesos pulmonares y tos. Presentan expectoración de diferentes características (esputo blanco, purulento o sanguinolento), fiebre entre 37.5 y $39^{\circ} \mathrm{C}$ en la mayoría de los casos, signos de obstrucción de la vía aérea, disnea, opresión del pecho y a la auscultación se escuchan crepitaciones y sibilancias en ambos pulmones (11). 
Los hallazgos radiológicos (radiografías y tomografías computarizadas) específicos comprenden desde opacidades reticulares hasta el compromiso consolidativo alveolar, presencia de derrame pleural en algunos casos, con hipoxemia de diferente grado de acuerdo con la severidad y respuesta clínica de los pacientes. En los casos de pacientes con broncoscopia se documentan secreciones en las vías respiratorias, mucosa bronquial congestiva, inflamación, edema, focos de hiperplasia y algunos de necrosis e incremento de eosinófilos circulantes en el 35\% de los pacientes (11).

Las muestras frecuentemente utilizadas para el diagnóstico son el lavado broncoalveolar y el esputo; no obstante, el escobillado de garganta podría usarse $(9,10)$. El diagnóstico de laboratorio se basa principalmente en la observación de la morfología parasitaria a través del microscopio de luz. Sin embargo, en algunos estudios se han confundido las células ciliadas del tracto respiratorio de los pacientes con L. blattarum y algunos protozoarios multiflagelados (12). El diagnóstico molecular se lleva a cabo a través de una reacción en cadena de polimerasa específica (PCR) donde se puede observar una banda de 214 pb que confirmaría el género Lophomonas spp (13).

Como se mencionó anteriormente, se cree que la inhalación de los aerosoles con los ooquistes de Lophomonas infecta a los humanos, pero también se considera la ingestión de comida contaminada con heces de cucarachas. Las condiciones higiénicas deficientes y la presencia de altas poblaciones de cucarachas en hábitats humanos se constituyen en factores de riesgo importantes (12).

La inmunosupresión es un factor que predomina en pacientes con estados nutricionales deficientes, exposición a condiciones higiénicas desfavorables y múltiples comorbilidades que limitan la respuesta inmune de los pacientes. El tratamiento se realiza con derivados de los nitroimidazoles como metronidazol. El tratamiento consiste en $500 \mathrm{mg}$ de metronidazol oral cada 8 a 12 horas o $2 \mathrm{~g}$ al día en adultos y 7.5 a $15 \mathrm{mg} / \mathrm{kg}$ cada 8 horas en niños durante una semana. Los casos graves se pueden tratar con metronidazol intravenoso $15 \mathrm{mg} / \mathrm{kg} / \mathrm{h}$ seguido de $7.5 \mathrm{mg} / \mathrm{kg} / 6 \mathrm{~h}$ como mantenimiento (13). Se describen otras alternativas terapéuticas con Tinidazol y Albendazol y hasta la presente no se han descrito casos fallidos relacionados con el manejo farmacológico (8).

Aunque es una rara enfermedad, la presencia cosmopolita de las cucarachas permite suponer que las infecciones por $L$. blattarum podrían ser más comunes de lo que se cree. Neumonías con o sin eosinofilia principalmente en pacientes inmunosuprimidos, deben ser consideradas por el médico al momento de realizar un diagnóstico clínico diferencial.

Existen 4.600 especies de cucarachas y de estas, solo se han identificado 30. Las cucarachas existen hace unos 320 millones de años, lo que corresponde con el periodo Carbonífero (14), así que habrá cucarachas por largo tiempo y por lo visto, tendremos que saber convivir con ellas y sus microorganismos.

\section{REFERENCIAS}

1. Adl SM, Simpson AGB, Farmer MA, Andersen RA, Andersen OR, Barta JR, et al. The new higher level classification of eukaryotes with emphasis on the taxonomy of protists. J Eukaryot Microbiol. 2005;52(5):399-451. [CrossRef] [PubMed] [Google Scholar].

2. Jian Xue, Ying-Li Li, Xue-Mei Yu, DaiKun Li, Ming-Fang Liu, Jing-Fu Qiu, et al. Bronchopulmonary Infection of Lophomonas blattarum: A Case and Literature Review. Korean J Parasitol. 2014; 52(5):521-525. [CrossRef] [PubMed] [Google Scholar]
3. Bittencourt-Silvestre J, Lemgruber L, de Souza W. Encystation process of Giardia lamblia: morphological and regulatory aspects. Arch Microbiol 2010; 192(4):259265. [CrossRef] [PubMed] [Google Scholar]

4. Zaragatzki E, Hess M, Grabensteiner E, Abdel-Ghaffar F, Al-Rasheid KAS, Mehlhorn $\mathrm{H}$. Light and transmission electron microscopic studies on the encystation of Histomonas meleagridis. Parasitol Res. 2010; 106(4):977-983. [CrossRef] [PubMed] [Google Scholar] 
5. Martínez-Girón R, Ribas A. Asthma, cockroaches, and protozoal forms: chance or not chance? Ann Allergy Asthma Immunol 2006; 97(6):818-819. [CrossRef] [PubMed] [Google Scholar]

6. Martínez-Girón R. Potential role of protozoa and tight junctions in the airway epithelium disruption. Clin Respir J 2011; 5(1):e6-e6. [CrossRef] [PubMed] [Google Scholar]

7. Chen SX, Meng ZX. Report on one case of Lophomonas blattarum in the respiratory tract. Chinese J Parasitol Parasit Dis. 1993; 11:28. (in Chinese) [Google Scholar]

8. Rahul Tyagi, Kavita Bala Anand, Kishore Teple, Rajkumar Singh Negi. Lophomonasblattarum infection in immunocompetent patient. Lung India. 2016; 33(6):667-668. [CrossRef] [PubMed] [Google Scholar]

9. He Q, Chen X, Lin B, Qu L, Wu J, Chen J. Late onset pulmonary Lophomonas blattarum infection in renal transplantation: a report of two cases. Intern Med. 2011; 50(9):1039-1043. [CrossRef] [PubMed] [Google Scholar].

10. Zhang CF, Zhang C, Gao HF. A case of bronchopulmonary infection caused by hypermastigote accompanied with tuberculosis and review of the literature. Chinese J Pract Intern Med. 2008; 28:10931094. (in Chinese) [CrossRef] [PubMed] [Google Scholar]
11. Rafael Martinez-Girón, Hugo Cornelis van Woerden. Lophomonas blattarum and brochopulmonary disease. Journal of Medical Microbiology. 2013; 62:1641-1648. [CrossRef] [PubMed] [Google Scholar]

12. Meng SS, Dai ZF, Wang HC, Li YX, Wei DD, Yang RL, Lin XH. Authenticity of pulmonary Lophomonasblattaruminfection: A case report. World J Clin Cases. 2019; 7(1):95101. [CrossRef] [PubMed] [Google Scholar]

13. Fakhar $M$, Nakhaei $M$, Sharifpour $A$, Kalani $H$, Banimostafavi ES, Abedi S, Safanavaei $S$, Aliyali M. First Molecular Diagnosis of Lophomoniasis: the End of a Controversial Story. Acta Parasitol. 2019; 64(2):390-393. [CrossRef] [PubMed] [Google Scholar]

14. Beccaloni G, Eades DC, Hopkins H. Cockroach Species File Online [on line]. 2014. [accessed 11 January 2019] URL Available in: http:// cockroach.speciesfile.org/ 